\title{
Создание атласа солнечной активности
}

\author{
Е.А. Илларионов ${ }^{1,3}$, А.Г. Тлатов ${ }^{2,3}$ \\ 1 МГУ, Москва \\ egor.mypost@gmail.com \\ 2 Кисловодская Горная астрономическая станция ГАО РАН \\ tlatov@mail.ru \\ ${ }^{3}$ КалмГУ, Элиста
}

Поступила в редакцию 16 ноября 2017 г.

Аннотация. В работе представлен результат разработки онлайн-атласа солнечной активности, который призван объединить в себе данные оперативного мониторинга и архивные наблюдения солнечной активности. Функционал, заложенный при разработке онлайн-атласа, а также гибкость технологий, с помощью которых он реализован, позволяют использовать его для визуализации и организации доступа к данным по всему спектру наблюдений Солнца. Сюда относятся наблюдения контуров и параметров активных областей, наблюдения солнечной короны, разнообразные ряды индексов солнечной активности, а также оперативные прогнозы. Атлас доступен по адресу в интернете www.observethesun.com. В настоящее время с его помощью представлены ежедневные наблюдения и архивные данные Кисловодской горной астрономической станции.

CREATING A SOLAR ACTIVITY ATLAS, by E.A. Illarionov, A.G. Tlatov. The paper presents the result of developing an on-line atlas of solar activity, which is designed to combine operative monitoring data and archival observations of solar activity. Atlas is available at www.observethesun.com. Currently, it provides daily observations and archival data from the Kislovodsk Mountain Astronomical Station.

Ключевые слова: Солнце, солнечная активность, базы данных

\section{1 Введение}

Для тех, кто каким-то образом задействует в работе наблюдательные данные по солнечной активности, несомненно знакома ситуация, когда для получения данных приходится преодолеть целый ряд трудностей различного характера. Довольно типичной ситуацией является отсутствие необходимых данных в открытом доступе. В лучшем случае это решается через личные контакты и пересылку по электронной почте, но чаще для их получения приходится ехать непосредственно в обсерваторию или другой институт. Ряд данных все же публикуется в открытом доступе, но здесь мы сталкиваемся с ситуацией, когда публикуется неполный архив и обновление происходит нерегулярно. Более того, формат данных зачастую оказывается непригодным для систематической обработки (например, если публикуются фотоизображения или ручные зарисовки вместо числовых массивов), либо к формату отсутствует документация (в этом случае неясно, как интерпретировать те или иные значения). 
Озвученные проблемы менее характерны для зарубежных наблюдательных данных, и отчасти в этом лежит причина их популярности в научных исследованиях. Вместе с тем этот факт вызывает тревогу и опасение за развитие отечественной службы Солнца. На наш взгляд, первостепенной задачей является консолидация потенциала наблюдений отечественных обсерваторий в единую согласованную базу, открывающую доступ к архивным наблюдениям, мониторингу текущей обстановки и прогнозу космической погоды. Разработанный сайт observethesun.com по своим возможностям имеет хорошие предпосылки для того, чтобы стать площадкой для подобной базы.

\section{2 Атлас солнечной активности}

Центральным компонентом атласа солнечной активности является трехмерная модель Солнца, которая позволяет визуализировать на своей поверхности различные типы активных областей. В отличие от плоской карты, 3D-модель можно поворачивать на любой угол для детального изучения строения области. При этом оказывается доступной для просмотра “темная" сторона Солнца, невидимая в данным момент с Земли. Таким образом, используя, например, данные наблюдений со спутников, можно создавать и просматривать карту активности на всей поверхности Солнца. На рис. 1 под разными углами показана 3D-модель Солнца, на которую нанесены некоторые типы активных областей.

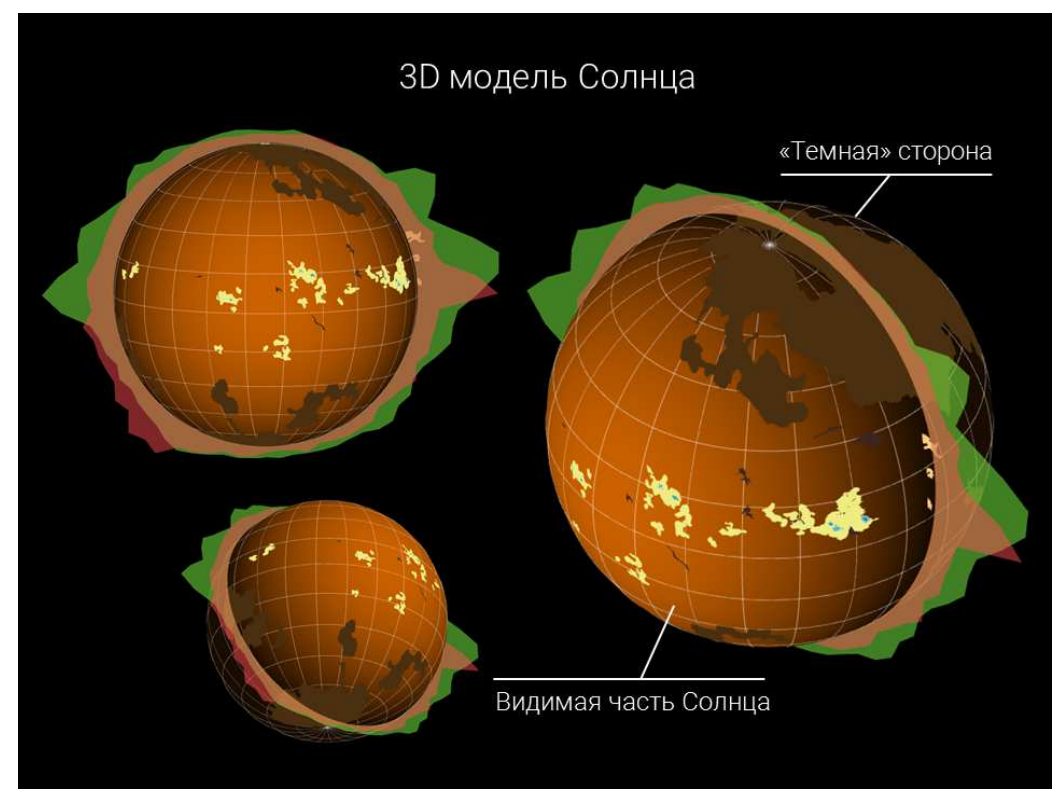

Рис. 1. Вид трехмерной модели Солнца под разными углами

Трехмерная модель имеет широкие возможности для наглядного представления наблюдений активных областей. На рис. 2 показано, как отображаются контуры солнечных пятен (ядра и полутень), волокна, флоккулы, корональные дыры, а также внефотосферные объекты, такие как протуберанцы и корона. Атлас обладает удобным и интуитивно понятным интерфейсом. В боковых и верхней части рабочей области располагаются элементы управления масштабом, выбора типа отображаемых областей и другие настройки карты. В нижней части располагается временная ось и календарь для быстрого перехода к нужной дате. Временная ось дополнительно отражает количество наблюдаемых объектов на каждый день. Внешний вид рабочей области представлен на рис. 3. 


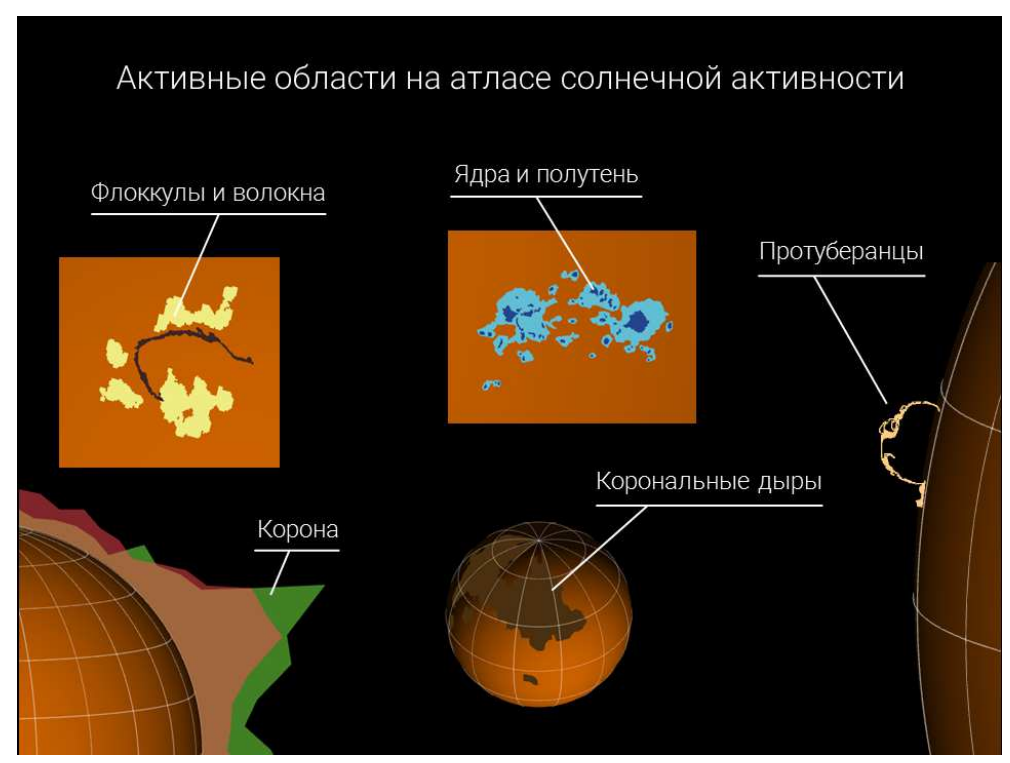

Рис. 2. Примеры отображения трассеров солнечной активности

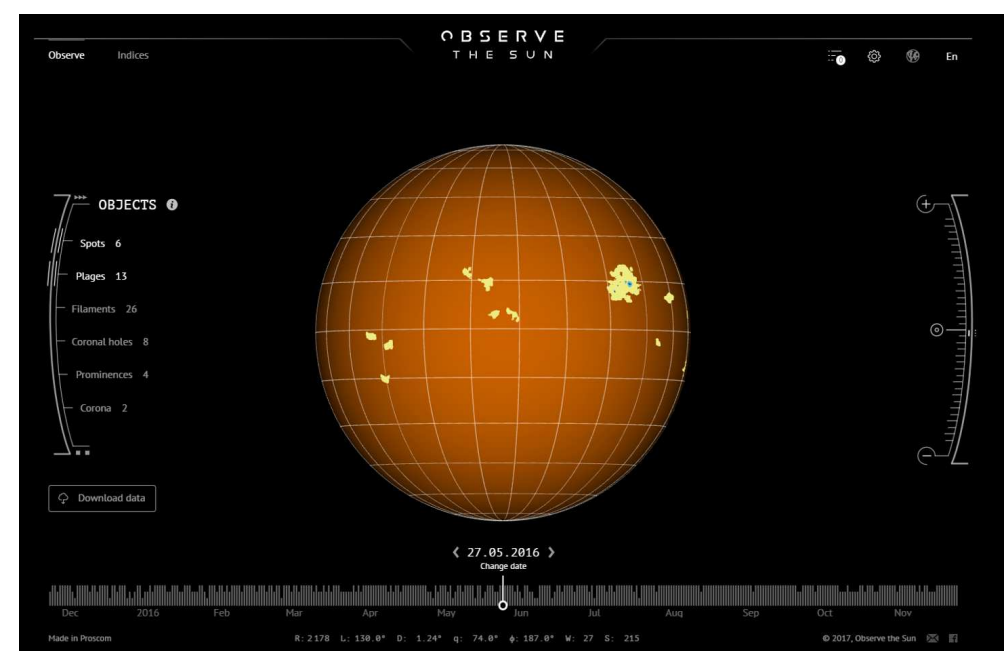

Рис. 3. Рабочая область атласа солнечной активности

При работе с активными областями зачастую возникает задача отследить изменения параметров активной области или ее формы с течением времени или сравнить между собой несколько активных областей. Для этого предусмотрен режим сравнения, достаточно отметить на карте интересующие области. На рис. 4 в режиме сравнения показано изменение параметров и формы одного и того же солнечного пятна.

Отметим, что любые данные, представленные в атласе, доступны для загрузки. Данные сохраняются в формате јson, который поддерживается всеми современными программами чтения данных и языками программирования. Другой тип информации, который отображается на сайте, - это графики временных рядов. С их помощью удобно визуализировать долговременные изменения индексов солнечной активности и их прогноз. Функционал сайта позволяет произвольным образом комбиниро- 


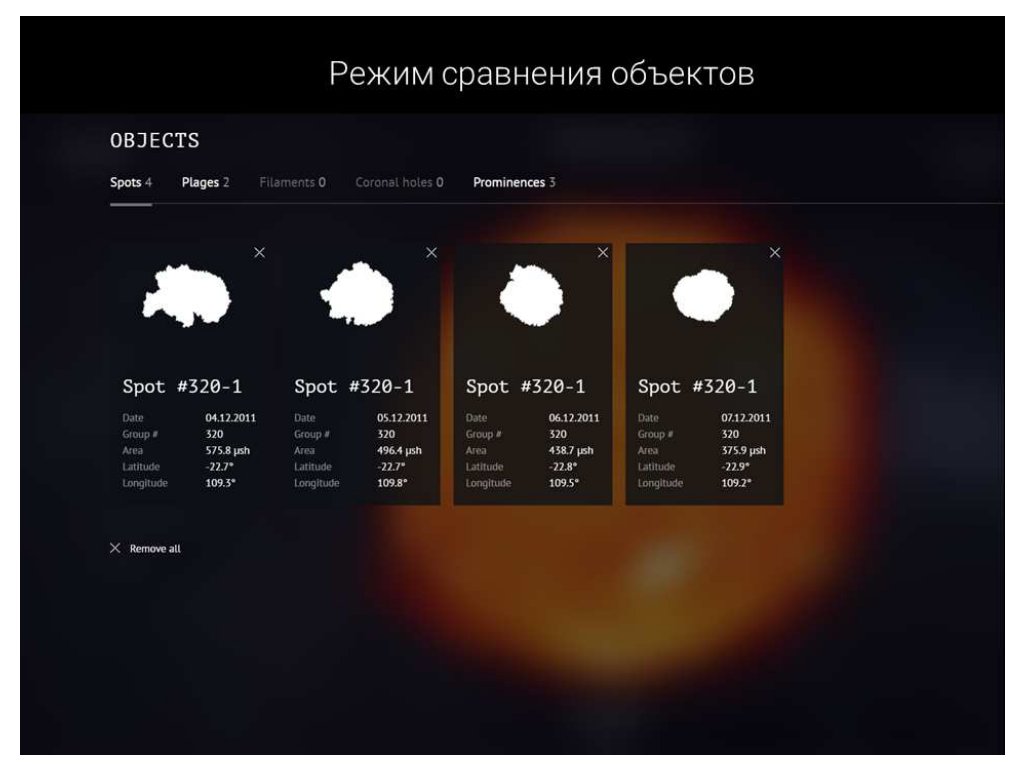

Рис. 4. Режим сравнения параметров солнечных пятен

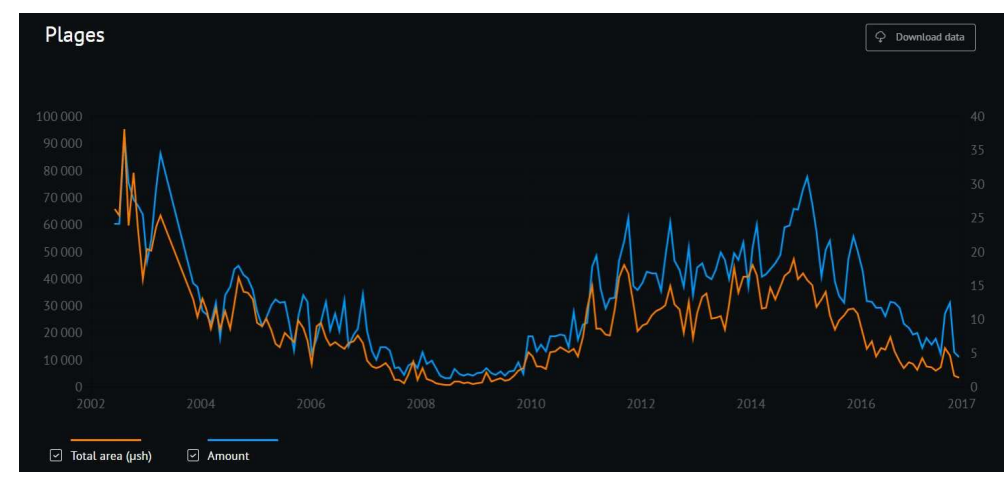

Рис. 5. Графики индексов солнечной активности (показаны суммарная площадь и количество флоккул за 2002-2017 гг.).

вать несколько графиков в одних и тех же осях, что весьма полезно для отслеживания взаимосвязи различных индексов. На рис. 5 показаны некоторые наборы графиков.

Для более детального исследования вариации индексов можно скачать данные с сайта и продолжить с ними работу в привычной программе.

Таким образом, с точки зрения функциональных возможностей разработанный атлас не имеет прямых аналогов в мире. Наиболее близким к нему ресурсом является сайт helioviewer.org (Мюллер и др., 2017), который визуализирует спутниковые наблюдения зарубежных миссий (российские данные на нем не представлены). Однако сайт не позволяет напрямую скачивать данные, а только предоставляет скрипты, которыми затем можно воспользоваться для загрузки данных из внешних источников. Другой популярный ресурс, solarmonitor.org (Хиггинс и др., 2011), воспроизводит лишь изображения с подписанными номерами активных областей. Выделение границ активных областей и расчет их параметров пользователю недоступны.

В настоящее время с помощью атласа солнечной активности представлен архив наблюдательных данных Кисловодской горной астрономической станции. Архив содержит информацию о контурах и 
параметрах активных областей более чем за столетний период и ежедневно пополняется оперативными наблюдениями. На их основе ведется расчет индексов активных областей, таких так число Вольфа, суммарная площадь пятен по всему диску и полушариям, суммарная площадь и количество флоккул, общая протяженность и количество волокон, площадь корональных дыр, количество и площадь протуберанцев, средняя интенсивность короны в линиях $6374 \AA$ и $5305 \AA$.

\section{3 Выводы}

В работе был дан обзор возможностей разработанного атласа солнечной активности по визуализации и организации доступа к различным типам данных по солнечной активности. Учитывая тот факт, что сегодня наблюдательные данные с российских обсерваторий крайне слабо представлены в открытом доступе, разработанный сайт мог бы стать объединяющей площадкой для создания единой точки доступа к данным и отражения полного спектра проявлений солнечной активности. Опыт взаимодействия с Кисловодской горной астрономической станцией показывает, что процесс интеграции данных в онлайн-атлас достаточно прост и не занимает длительного времени. Вместе с тем открытый доступ к данным, с одной стороны, повышает требования к качеству публикуемых материалов, а с другой позволяет всем желающим использовать их для научных исследований.

Работа выполнена при поддержке проекта РНФ №15-12-20001.

\section{Литература}

Мюллер и др. (D. Muller, B. Nicula, S. Felix, F. Verstringe, B. Bourgoignie, et al.) // Astron. Astrophys. 2017. V. 606. id. A10.

Хиггинс и др. (Higgins P.A., Gallagher P.T., McAteer R.T.J., Bloomfield D.S.) // Adv. Space Res. 2011. V. 47. P. 2105. 